\title{
A Literatura Infantojuvenil na aula de História
}

\section{(Literature for children and adolescents in the history class)}

\author{
Liliana ROCHA \\ Docente do Ensino Básico e Secundário \\ Ministério da Educação e Ciência de Portugal
}

\begin{abstract}
RESUMO: A relação entre a Literatura e a História é imemorial, mas só no último século o cruzamento entre as duas permitiu à História aceitar a Literatura enquanto testemunho para promover situações de aprendizagem nas aulas de História. A promoção da leitura nas escolas tem vindo a melhorar os resultados de literacia dos alunos, nomeadamente em termos de riqueza vocabular, de escrita, de oralidade, de criatividade e de imaginação. Nesta senda, o nosso estudo incidiu sobre a viabilidade da utilização da literatura infantojuvenil nas aulas de História, no terceiro ciclo do ensino básico, enquanto recurso didático para promover aprendizagens significativas e a compreensão contextualizada. Para concretizar a nossa intenção, recorremos à leitura de excertos do livro O Mistério das Catacumbas Romanas da autora Mafalda Moutinho, à técnica de inquérito por questionário e à produção de narrativas pelos alunos.
\end{abstract}

PALAVRAS-CHAVE: Literatura infantojuvenil; Didática da História; Compreensão Histórica; Empatia Histórica; Narrativa Histórica.

ABSTRACT: The relationship between literature and history is immemorial, but only in the last century has the junction between the two allowed history to embrace literature as a testimony to promote learning situations in history classes. The promotion of reading in schools has improved pupils' literacy results, particularly in terms of their vocabulary, writing, oral skills, creativity and imagination. In this sense, our study has focused on the viability of the use of children's literature in history classes in the third cycle of basic education, as a didactic resource to promote meaningful learning and contextualized understanding. To carry out our study, excerpts from the book The Mystery of Roman Catacombs by Mafalda Moutinho were read, the questionnaire survey technique was used and students were asked to write stories.

KEY WORDS: Literature for children and adolescents; history didactics; understanding history; historical empathy; historical narrative.

\section{Introdução}

O conceito de literatura infantojuvenil não é consensual entre os vários autores que se debruçam sobre esta temática. Consideram que crianças e jovens são públicos distintos, vivem estádios de desenvolvimento diferentes, logo os interesses não são os mesmos, e isso reflete-se nas leituras que procuram. 
Contudo, após a leitura de vários estudos e diferentes conceções, adotamos o termo literatura infantojuvenil por nos parecer mais adequado a este tipo de literatura utilizada no nosso estudo.

O livro assumiu-se, ao longo do tempo, como elemento fundamental no desenvolvimento sócio-cognitivo da criança pois a leitura enriquece o seu vocabulário, melhora a sua ortografia, aperfeiçoa a sua capacidade de redação e amplia permanentemente os seus horizontes culturais (...) ajuda a crescer, a amadurecer e a superar obstáculos e dificuldades da vida (...) levando-o a imaginar, a pensar, a criticar e a conhecer (Mesquita, 2011:2-3).

A Literatura enquanto fonte permite construir uma versão da verdade dos factos quando analisada à luz do contexto histórico no qual foi produzida, pois é essa a base da produção ficcional. Nesta senda, ao utilizar obras literárias ou excertos dessas nas aulas de História, o professor deverá chamar os alunos à realidade pois há necessidade de situar ao aluno que a passagem selecionada retrata determinado contexto histórico, com referências a pessoas, lugares e a utilização de linguajares que transparecem a ideia, os sentimentos do(s) seu(s) autor(es) (Rachadel; Felisberto; Venera, 2010:16).

Ou seja, é possível um diálogo entre a Literatura e o Ensino de História se se realizar o exercício de compreensão de como a Literatura utiliza a História através da escrita, e de uma linguagem própria capaz de fazer imaginar uma determinada época, e de como a segunda prevê a utilização da primeira como uma fonte através da sua interpretação, da leitura dos pensamentos de alguns personagens para fazer sobressair os valores presentes em dadas sociedades e épocas (Ibid.).

Partindo do princípio de que a leitura melhora a capacidade de redação do aluno, decidimos utilizar uma estória infantojuvenil como recurso didático nas aulas de História, adequada a uma temática, e analisar as narrativas dos alunos e a compreensão histórica realizada a partir da obra literária.

Segundo Regina Ribeiro (2011:2) os estudos realizados recentemente sobre educação histórica ${ }^{1}$ referem que:

"a identificação e compreensão dos processos de aprendizagem e construção do pensamento histórico devem ser realizadas por meio da análise das produções dos estudantes, especialmente as narrativas elaboradas em contextos de aula."

Segundo Rüsen, as produções escritas dos alunos organizam a compreensão dos sujeitos sobre os acontecimentos, as ações das pessoas no passado e, assim, expressam uma consciência histórica (2007 cit. por Ribeiro, 2011:3). Ou seja, a leitura de narrativas (ou a produção delas) ou de textos históricos contribuem para a qualidade do que se compreende e do que se aprende sobre História. De acordo com Kieran Egan (1983, 1994 cit. por Parente, 2004:34), a narrativa deveria ser utilizada como técnica de ensino, no sentido de

\footnotetext{
${ }^{1}$ No domínio do Ensino da História, a Educação Histórica é a linha de investigação em que os investigadores mais se têm focado. A Educação Histórica procura estudar as ideias históricas dos alunos, analisando o papel e o significado da História para esses. E entre vários aspetos, os pesquisadores centram-se nas estratégias de ensino e aprendizagem, ou seja, nas características do processo de construção do pensamento histórico.
} 
estruturar conteúdos de aprendizagem de modo a torná-los mais eficientes e significativos e, sendo tão valiosa para a compreensão histórica poderia formar a base principal do currículo elementar da História. $\mathrm{O}$ aluno ao analisar um facto ou acontecimento e ao construir a sua interpretação através da narrativa, associa um conjunto de atitudes, procedimentos e competências como a curiosidade, empatia, imaginação e a interpretação de fontes que se torna evidência empírica (Barca, 2010:23). Ora, em Educação Histórica, o termo empatia é fulcral para a compreensão histórica. Segundo Andrade et al. (2011:261), a empatia histórica é a capacidade de um sujeito se colocar no lugar de outro, de tentar pensar e ver o mundo com outros olhos, outras mentalidades, ainda que esses sujeitos sejam separados por longo período temporal. Implica descentramento do aluno e dos seus pontos de vista no presente e deslocação para outro tempo, e imaginação para criar mundos históricos do qual fará parte como ator (Rosanvallon, 1996 cit. por Andrade et al., 2011:261).

\section{Metodologia do estudo}

Para concretizarmos a nossa investigação adotamos a análise qualitativa porque é uma análise naturalista e rica em pormenores descritivos, e a análise quantitativa.

A investigação-ação realizou-se numa escola portuguesa, no distrito do Porto, no ano letivo 2012/2013, com alunos de duas turmas de $7 .^{\circ}$ ano de escolaridade $\left(7 . .^{\circ} \mathrm{C}\right.$ e $\left.7 . .9 \mathrm{D}\right)$, com idades entre os 12 e os 13 anos.

Tínhamos como objetivo central compreender a importância da literatura infantojuvenil como recurso didático nas aulas de História e o seu contributo na construção do conhecimento histórico dos alunos de terceiro ciclo do ensino básico.

Assim, inicialmente guiámo-nos por duas questões orientadoras:

- Quais os hábitos de leitura dos alunos do terceiro ciclo?

- Que conhecimentos substantivos constroem os alunos com o uso da literatura infantojuvenil?

Na primeira experiência didática iríamos lecionar o tema 1 - Das sociedades recoletoras às primeiras civilizações, nomeadamente a unidade 1.3 Uma civilização dos Grandes Rios, e mais especificamente a subunidade Origem das primeiras civilizações, do Programa de História do $7 .^{\circ}$ ano de escolaridade. Para essa intervenção didática selecionamos o livro O Segredo do Mapa Egípcio da autora Mafalda Moutinho porque após a sua leitura constatamos que se adequava ao conteúdo que iríamos lecionar. No entanto, essa primeira intervenção didática (exploratória) revelou-se insuficiente para responder às questões orientadoras inicialmente propostas para este trabalho de investigação-ação, pois os alunos não leram a obra a priori como solicitado, o que os impediu de participarem ativamente na aula, e conduziu o professor ao domínio da mesma.

A reflexão sobre esta primeira experiência exploratória e a revisão de literatura sobre estudos em cognição histórica conduziu-nos à reformulação de alguns dos objetivos e das estratégias a implementar. 
Numa primeira etapa decidimos redefinir a abordagem à literatura infantojuvenil no processo de ensino-aprendizagem da História. Para além das duas primeiras questões orientadoras, decidimos avaliar, também, o tipo de narrativas construídas pelos alunos a partir da leitura/uso de excertos do "novo" recurso didático-pedagógico e categorizar as ideias históricas, por eles manifestadas, no domínio da compreensão contextualizada (empatia histórica). Desta forma, foi necessário definir mais questões orientadoras da nossa investigação. E, assim, decidimos que precisávamos de saber:

- Que tipo de narrativas constroem os alunos a partir da literatura infantojuvenil?

- Que relevância atribuem os alunos à utilização da literatura infantojuvenil na construção do conhecimento histórico?

De seguida, decidimos alargar a amostra da nossa investigação, através da definição de um grupo experimental (onde aplicaríamos a literatura infantojuvenil enquanto recurso didático nas aulas) e um grupo de controlo (onde a literatura infantojuvenil não seria utilizada). Estes dois grupos permitiriam estabelecer um termo de comparação e realizar determinadas inferências e produzir conclusões mais sustentadas.

A recolha de dados realizou-se de forma sequencial, e a informação que cada um dos momentos nos fornecia sugeria a aplicação do instrumento seguinte. Ao longo do processo de investigação-ação aplicamos os seguintes instrumentos:

- um inquérito por questionário - Hábitos de leitura - cujo objetivo era conhecer os hábitos de leitura da população que compunha a nossa amostra, e que determinaria o grupo experimental e o grupo de comparação;

- um inquérito por questionário ao grupo experimental - A Literatura Infantojuvenil nas aulas de História (e para controlo, um inquérito por questionário ao grupo de controlo) - cujo objetivo era conhecer o contributo da literatura infantojuvenil na intervenção didática;

- a elaboração de duas narrativas, com tópicos de orientação, sobre uma temática lecionada (com e sem a utilização da literatura infantojuvenil);

- um teste de avaliação sumativa, aplicado a ambas as turmas;

- um inquérito por questionário - A Literatura Infantojuvenil no ensino da História, aplicado no grupo experimental com o qual pretendíamos avaliar a relevância atribuída pelos alunos ao uso da literatura infantojuvenil na construção do seu conhecimento histórico, bem como a pertinência do uso deste recurso didático de forma mais sistemática nas aulas de História.

O questionário sobre os hábitos de leitura dos alunos era anónimo e era composto por um leque de questões que abordavam desde a frequência de leitura, à quantidade de livros lidos, aos tipos de livros que os alunos liam, à forma como adquiriam os livros e ao significado pessoal da importância da leitura. $A$ análise às respostas aos questionários permitiu-nos definir a turma do 7.- $\mathrm{C}$ como o grupo experimental e a turma do 7.- $\mathrm{D}$ como o grupo de controlo. 
De seguida, escolhemos outro conteúdo temático, para uma nova intervenção didática, e uma segunda obra da mesma autora, Mafalda Moutinho. Seguindo a planificação anual da disciplina, avizinhava-se o tema 2 - A Herança do Mediterrâneo Antigo, unidade 2.2. - O Mundo Romano no apogeu do Império, o qual se adequava à obra O Mistério das Catacumbas Romanas da autora referida.

Nesta senda, indicamos a leitura da obra aos alunos da turma do 7.. $\mathrm{C}$ e planificamos três regências para cada turma, que contemplaram o estudo da origem da civilização romana, a sociedade romana e o poder imperial e o urbanismo romano.

As primeiras intervenções didáticas realizaram-se nos dias 14 e 17 de janeiro de 2013 na turma do 7.. $\mathrm{D}$ e do $7 . . \mathrm{C}$ respetivamente. Conforme as planificações, as aulas incidiriam sobre o estudo das origens da cidade de Roma e a expansão romana. No caso da turma do $7 . . \mathrm{D}$, a professora utilizou recursos didáticos tradicionais, apoiados por uma apresentação em powerpoint. Num primeiro momento revelou-se propositado a apresentação da lenda das origens de Roma através de uma ficha de trabalho que continha no verso questões sobre a lenda. De seguida, para os alunos compreenderem a dimensão do Império Romano bem como as conquistas efetuadas pelos romanos, a professora utilizou várias fontes como cronologias e mapas para os discentes estabelecerem uma comparação com a civilização grega estudada anteriormente. Através de fontes primárias escritas, os alunos foram conduzidos ao estudo das causas da expansão romana e dos fatores de romanização. Ainda antes do término da aula, os alunos realizaram uma ficha de trabalho para consolidar as aprendizagens. No final, foi proposto aos alunos o preenchimento do questionário cujas questões abordavam o contributo dos recursos didáticos utilizados nessa aula para a construção do conhecimento histórico dos alunos.

No caso da turma grupo experimental $\left(7 .^{\circ} \mathrm{C}\right)$, recorremos sobretudo à leitura de excertos da obra $O$ Mistério das Catacumbas Romanas para lecionar a temática sumariada, e a condução da aula foi feita através de indicações dadas pelos Primos (personagens da obra literária), integradas na apresentação em powerpoint. Ou seja, para criar um maior envolvimento dos alunos com os personagens, as indicações sobre o tema a estudar na aula eram dadas pelos Primos através de missivas. Por outro lado, pelo facto de nem todos os conteúdos programáticos, definidos nas orientações curriculares, constarem da obra selecionada, e dado ser possível contactar com Os Primos e/ou a autora através do site eletrónico (www. osprimos.com), a professora simulou ter recebido um e-mail dos adolescentes sobre a lenda da Loba Capitolina, por julgar estimulante como introdução ao estudo da civilização romana. A leitura da lenda bem como a realização dos exercícios de consolidação foram sugeridos pelos Primos, assim como as restantes atividades previstas na planificação. No final desta aula, os alunos foram convidados a preencher o questionário sobre os contributos da literatura infantojuvenil na construção do seu conhecimento histórico.

A sociedade romana e o poder imperial eram os próximos subtemas a lecionar. Assim, a segunda aula realizada na turma do $7 . . \mathrm{D}$, aconteceu no dia 22 de janeiro de 2013 , e a do $7 . .-$ $\mathrm{C}$ aconteceu no dia 24 do mesmo mês. De acordo com a planificação da turma grupo de controlo, a professora usou o suporte powerpoint para apresentar recursos didáticos diversificados, 
necessários ao processo de ensino-aprendizagem, e o diálogo para orientar os alunos na sua interpretação, produção de inferências e formulação de conclusões. Utilizou também documentos iconográficos para os alunos identificarem personalidades que marcaram cada um dos períodos políticos da história de Roma; documentos escritos; esquemas e a mapas propostos no manual adotado. No final da aula, para além do momento de consolidação de conhecimentos, os alunos foram convidados a elaborar uma narrativa, que deveria ter entre 20 a 30 linhas, sobre o Imperador Romano Otávio Augusto. A proposta de atividade apresentava alguns tópicos de orientação:

- descrição física e psíquica do imperador;

- os poderes que o imperador possuía;

- as medidas tomadas (pelo imperador) para manter um clima de paz (Pax Romana) num império tão vasto.

Essas orientações procuravam evitar a dispersão do aluno, incorporar os conteúdos programáticos lecionados na aula, bem como avaliar os conhecimentos adquiridos na aula anterior. Com esta narrativa pretendíamos, ainda, analisar o tipo de narrativas que os alunos constroem a partir de uma aula com uma diversidade de recursos didáticos ditos "tradicionais".

No caso da turma do 7. C, a planificação da aula previa estratégias de ensino-aprendizagem que incluíam a leitura de excertos do livro O Mistério das Catacumbas Romanas. A leitura de excertos no início da aula deveu-se a duas razões: primeiro, os excertos serviam de motivação para iniciar o estudo da temática; e, em segundo, os excertos selecionados estavam diretamente relacionados com a atividade final proposta aos alunos: a elaboração de uma narrativa que tinha como título "Se eu fosse um Imperador Romano..." e sugeria a seguinte tarefa: "Imagina que eras o Imperador Nero (37 d.C. - 68 d.C.) e que surpreendias os Primos quando eles visitaram a Domus Aurea."

À semelhança da narrativa proposta aos alunos da turma grupo de controlo, esta também indicava alguns tópicos de orientação, tais como:

- a sua descrição física e psíquica (enquanto imperador);

- os poderes que possuía enquanto imperador;

- as razões que o levaram a construir a Domus Aurea e os materiais com que a embelezaste.

A narrativa devia ter entre 35 e 45 linhas. A alteração do nome do imperador e do último tópico orientador, comparativamente às orientações da narrativa do $7.0 \mathrm{D}$, deveuse ao facto de se tratar de conteúdos abordados na obra infantojuvenil e parecer óbvia a integração desta na narrativa do grupo experimental.

A terceira aula na turma do $7 . .0 \mathrm{D}$ aconteceu no dia 28 de janeiro de 2013 , e no $7 . .9 \mathrm{C}$ no dia 31 desse mês. Nesta aula estudaram-se aspetos da vida quotidiana em Roma e a padronização do urbanismo de cidades romanas. Na turma do $7 .-\mathrm{D}$, a professora utilizou, novamente, uma apresentação em powerpoint, o manual adotado e o diálogo orientado, 
e recorreu a fontes primárias e fontes secundárias para apoiar o processo de ensinoaprendizagem. No final da aula, os alunos resolveram os exercícios de consolidação das aprendizagens e, realizaram outra narrativa sobre a vida quotidiana de um Senador, intitulada "Se eu fosse um Senador Romano...". O aluno deveria imaginar-se um Senador e como seriam os momentos passados nas Termas de Trajano. Para realizar a narrativa, 0 aluno deveria seguir, igualmente, alguns tópicos de orientação, tais como:

- a sua descrição física e psíquica (enquanto Senador);

- os seus poderes/funções (enquanto Senador);

- as pessoas com quem se relacionava;

- a importância de frequentar as termas diariamente.

A narrativa não deveria ultrapassar as 30 linhas.

Na turma do 7. C -grupo experimental- a aula começou com a leitura de vários excertos da obra $O$ Mistério das Catacumbas Romanas, cujo conteúdo foi sustentado com a visualização de um vídeo sobre duas construções romanas, o Coliseu e o lago artificial da Domus Aurea. Para além destes recursos, a professora também usou documentos escritos e iconográficos para representar a padronização e a utilidade das construções romanas. Após a consolidação dos conhecimentos, através de uma ficha de trabalho, os alunos foram convidados a elaborar uma nova narrativa intitulada "Se eu fosse um Gladiador Romano..." dado que o estudo das construções romanas e os excertos lidos na sala de aula relacionavam-se com o Coliseu, local onde se desvendaram todos os mistérios da obra infantojuvenil estudada. A elaboração desta narrativa apelava à mudança do final da história: "Imagina que eras o Gladiador e que podias mudar o final da história. Então, imagina que o encontro final se passava no Coliseu e que descobrias as intenções dos bandidos. O que aconteceria?". A produção escrita deveria ter entre 35 e 45 linhas e obedecer aos seguintes tópicos:

- a descrição do Coliseu;

- a descrição física e psicológica do Gladiador;

- quem eram os gladiadores e o que faziam;

- qual a reação do Gladiador (aluno) e os sentimentos despertados pela situação a que assistia.

A diferença do número de linhas disponibilizadas para as narrativas do grupo experimental e do grupo de controlo deveu-se ao facto do primeiro grupo ter de se basear na obra infantojuvenil estudada nas aulas e, portanto, esperar-se uma narrativa mais extensa e mais recheada de pormenores.

Com estas atividades pretendíamos analisar o tipo de narrativas que os alunos constroem a partir da literatura infantojuvenil, avaliar a compreensão contextualizada (empatia histórica) e categorizar as ideias históricas por eles manifestadas. 
Após a conclusão do estudo da unidade didática procedeu-se à avaliação dos conhecimentos dos alunos do grupo experimental e do grupo de controlo através de um teste de etapa. A estrutura do teste do $7 .{ }^{\circ} \mathrm{C}$ seguiu a metodologia utilizada pela professora nas suas aulas, ou seja, as questões eram acompanhadas por pequenos excertos retirados da obra estudada, 0 Mistério das Catacumbas Romanas, e que tinham sido analisados em contexto de sala de aula.

As questões que integraram os testes de avaliação contemplavam as Metas de Aprendizagem (MA) definidas para a disciplina de História, no terceiro ciclo do ensino básico. Por essa razão, as questões apelavam à compreensão temporal (MA 1), à compreensão espacial (MA 4), à compreensão histórica contextualizada (MA 8), à comunicação em História (MA 12), e com maior incidência à interpretação de fontes (MA 6).

A comparação dos resultados destes dois documentos permitiu-nos avaliar o contributo da literatura infantojuvenil para o processo de ensino-aprendizagem da História, bem como refletir sobre possíveis contributos para melhorar o processo de ensino.

Numa fase final (dia três de junho de 2013) aplicámos o inquérito por questionário $A$ Literatura Infantojuvenil no ensino da História no grupo experimental, composto maioritariamente por questões abertas, com o qual pretendíamos avaliar a relevância atribuída pelos alunos ao uso da literatura infantojuvenil na construção do seu conhecimento histórico, bem como a pertinência da continuidade deste recurso didático nas aulas de História.

\section{Análise de dados}

\section{A Literatura Infantojuvenil nas aulas de História}

No final das duas primeiras intervenções didáticas, realizadas nos dias 14 e 17 de janeiro de 2013 , nos grupos de controlo e experimental respetivamente, foi solicitado aos alunos que respondessem a um questionário sobre o contributo dos recursos didáticos, utilizados nas respetivas aulas, para a construção do seu conhecimento histórico. A primeira parte do questionário destinava-se à caraterização do aluno, e a segunda parte era composta por questões predominantemente abertas sobre os recursos didáticos utilizados nas aulas. Por isso, elencamos no questionário os recursos didáticos e as estratégias utilizadas nas aulas de cada turma.

Da análise quantitativa das respostas dos alunos, podemos concluir que, os recursos mais apreciados pelo grupo de controlo foram a internet; o excerto do filme Gladiador, imagens, mapas e documentos escritos. No entanto, os alunos revelaram ter aprendido mais através da apresentação digital (powerpoint) tendo sido este recurso apontado como 0 aspeto mais relevante da aula. Foi através deste recurso também que os alunos referiram ter aprendido novos conceitos, sendo o de Romanização o mais assinalado. Relativamente às estratégias, as mais apreciadas foram as sínteses orais e escritas e o diálogo orientado pelo professor. Segundo os alunos, foi simultaneamente através do diálogo orientado pelo professor que aprenderam vocabulário novo, nomeadamente o termo Romanização.

Relativamente ao grupo experimental, embora nem todos os alunos tivessem lido a obra no início do seu estudo, metade da turma, no final da aula, considerou a literatura infanto- 
juvenil como um recurso didático muito positivo na construção do conhecimento histórico. Onze alunos classificaram-na de interessante e divertida, com a qual adquiriram vocabulário novo, tendo sido o conceito de Romanização o mais apontado também por este grupo. Doze alunos revelaram que sentiram curiosidade em pesquisar mais informação sobre o conteúdo da estória depois de a ler, e concluíram que esta foi uma mais-valia para a aula de História, tendo sido assinalada como um dos aspetos mais relevantes de toda a aula.

\section{A narrativa na aula de História}

Como já referimos, a nossa investigação-ação centrou-se nas narrativas elaboradas pelos alunos a partir de recursos didáticos "tradicionais" - grupo de controlo, e da obra literária infantojuvenil O Mistério das Catacumbas Romanas - grupo experimental. O nosso objetivo era categorizar as ideias históricas manifestadas pelos alunos, no domínio da compreensão contextualizada (empatia histórica), e que adiante designam-se por NA D (Narrativas dos Alunos do $7 .^{\circ}$ D, grupo de controlo) e NA C (Narrativas dos Alunos do 7.. C , grupo experimental). Para tal, adotamos os procedimentos metodológicos recomendados na análise de conteúdo mais complexa, designada por Grounded Theory (Glaser y Strauss, 1967; Strauss, 1987; Strauss e Corbin, 1991) e, para a análise das narrativas dos alunos, baseamo-nos nas categorias criadas por Parente (2004), presentes na sua dissertação de mestrado, intitulada A Narrativa na Aula de História. Dentro deste quadro metodológico, começamos por separar, examinar e comparar os dados para depois conceptualizar e categorizar as informações obtidas (Parente, 2004:90).

Num primeiro momento, analisámos as narrativas produzidas por ambos os grupos à luz das metas de aprendizagem definidas para a disciplina de História no 7. ano. No momento seguinte, procedemos à sua análise de conteúdo. Comparámos narrativas e através de um processo de codificação aberta, organizámos conjuntos de NA com estruturas idênticas, dentro de cada turma. Resultaram quatro níveis de elaboração das narrativas (de um menos elaborado para um mais elaborado), o que nos permitiu compreender que tipos de narrativas constroem os alunos a partir dos recursos didáticos utilizados no processo de ensino-aprendizagem, e categorizar as ideias históricas dos alunos no domínio da compreensão contextualizada (empatia histórica).

Devemos salientar que nem todos os alunos entregaram as duas atividades propostas em cada turma, daí só termos conseguido metade da amostra pretendida, e por essa razão o aluno D1 (grupo de controlo) na primeira narrativa produzida não corresponde ao mesmo indivíduo identificado por D1 na segunda narrativa, passando-se exatamente o mesmo no grupo experimental, porque os números foram atribuídos aleatoriamente às narrativas não considerando a identificação do aluno.

De seguida, iniciamos a análise das narrativas à luz das metas de aprendizagem definidas para 0 7. ano, nomeadamente a Meta de Aprendizagem Intermédia 7 - 0 aluno descreve, sucintamente, como vivia e interagia a sociedade romana, indicando de forma implícita ou explicita alguns condicionalismos, motivações e consequências da ação hu- 
mana (Compreensão histórica contextualizada)². Primeiro identificámos as narrativas que, em cada grupo, respeitavam a essência do enunciado e os respetivos tópicos de orientação para a realização da atividade, e depois verificamos quais as NA, quer no grupo de controlo quer no grupo experimental, que apresentavam um texto estruturado (ou seja, que apresentavam uma introdução, desenvolvimento e conclusão) e um fio condutor entre a criatividade e os conhecimentos adquiridos nas aulas de História.

Após essa análise estabelecemos uma comparação entre as narrativas produzidas e concluímos que:

- havia uma progressão no desempenho dos alunos nas narrativas produzidas pelo grupo de controlo. Verificaram-se melhorias significativas quer na originalidade, quer na estrutura e coerência do texto, quer no cumprimento dos tópicos do enunciado, quer na demonstração de conhecimentos e aprendizagens realizadas na aula de História;

- no caso das narrativas construídas pelo grupo experimental, verificou-se, de uma forma geral, um melhor desempenho dos alunos na primeira narrativa "Se eu fosse um Imperador Romano...". Ou seja, os alunos revelaram uma maior criatividade na elaboração da sua estória e conseguiram demonstrar a aplicação das aprendizagens realizadas em sala de aula, de forma mais evidente. Destacou-se a narrativa do aluno $\mathrm{C6}$, em todos os parâmetros analisados. Verificou-se igualmente que as narrativas $\mathrm{C6}, \mathrm{C7}$, C9 e C10 evidenciavam claramente os tópicos exigidos no enunciado da tarefa, destacando-se esses alunos na narrativa "Se eu fosse um Gladiador Romano...". Ou seja, embora o panorama fosse mais positivo na tarefa "Se eu fosse um Imperador Romano...", foi na tarefa "Se eu fosse um Gladiador Romano..." que se verificou um maior número de narrativas mais completas, de acordo com os parâmetros de avaliação;

- comparando as primeiras NA D e as NA C a avaliação foi mais positiva, em geral, no grupo experimental em todos os parâmetros de avaliação, embora fosse no grupo de controlo que se registasse um maior número de alunos (D6 e D8) com melhor desempenho em todos os parâmetros, mas também com pior desempenho (D5, D10 e D11);

- comparando as segundas NA D e as NA C, concluímos que os resultados eram mais positivos no caso das NA C, à exceção do parâmetro que avaliava a originalidade $\mathrm{e}$ criatividade. No caso das NA C destacaram-se as narrativas de quatro alunos (C6, C7, C9 e C10) em todos os parâmetros, enquanto que, nas NA D apenas se destacaram as narrativas de dois alunos: D1 e D4. Nas NA D verificou-se também uma maior dificuldade dos alunos em aplicarem aprendizagens realizadas nas aulas de História (D9, D10, D11, D12 e D13), bem como na elaboração de um texto estruturado e coerente (D7, D13 e D14). Podemos concluir que os resultados foram mais positivos no grupo experimental.

${ }^{2} \mathrm{http}: / /$ metasdeaprendizagem.dge.mec.pt/ensino-basico/metas-de-aprendizagem $/$ metas/?area=5\&level=6 (consultado em 09/09/2013). 
Posteriormente realizámos uma triagem e agrupamos conjuntos de NA com estruturas idênticas, quer no grupo experimental quer no grupo de controlo. Assim, obtivemos quatro categorias de narrativas, a partir das quais definimos quatro níveis de elaboração que vão do menor ao maior grau de elaboração, e aos quais correspondem diferentes níveis de compreensão histórica. No final da triagem e agrupamento de conjuntos de narrativas concluímos que os alunos do grupo experimental apresentaram melhores resultados comparativamente ao grupo de controlo. Por exemplo, no grupo experimental, registamos mais narrativas no nível quatro (Descrição Explicativa Contextualizada) e mais narrativas no nível três (Descrição Explicativa). E, embora, no grupo experimental se registassem 14 narrativas no nível dois (Descrição Simples) e, no grupo de controlo se registassem oito, foi neste último, que se registou um maior número de narrativas fragmentadas e sem coerência (11 narrativas).

A estes quatro níveis de elaboração da narrativa, que se distribuem entre o menor e o maior grau de elaboração, correspondem diferentes níveis de compreensão histórica. De seguida, apresentámos um exemplo de NA para cada um desses níveis, tendo o cuidado de os distribuir equitativamente entre o grupo experimental e o grupo de controlo. Segue-se a apresentação de exemplos de diferentes níveis conceptuais encontrados nas narrativas dos alunos, que são acompanhados pela análise de conteúdo de cada narrativa.

\section{EXEMPLO 1}

\section{Nível 1 - FRAGMENTOS}

\section{Caracterização}

Narrativa não visível ou visível mas vaga, com frases soltas sem ligação entre os passos. Utilização de referências espaciotemporais, factos, acontecimentos e protagonistas, sem grande rigor histórico, apresentados através de uma sequência organizativa simples. Não responde às indicações do enunciado, e não evidencia compreensão histórica.

Narrativa sem criatividade.

Exemplo de narrativa dos alunos neste nível: NA D11.

\section{Transcrição da NA D11}

"Se eu fosse um Senador gostava de andar arranjado, ir ao barbeiro, via espectáculos. Era alto e não gostava que se mete-sem na minha vida.

Tinha o poder de mandar em todos e quem desobedesse às minhas ordens seria castigado.

Não havia plebeus, eramos todos iguais

Relacionava-me mais com as pessoas nas termas, e depois oferecia-lhes um banquete.

Frequentava as termas diariamente por causa dos meus amigos plebeus e para conviver.

De manhã ia ao barbeiro, depois ia almoçar. Logo em seguida ia a museus e depois do banquete à noite ia a espectáculos.

Protegeria sempre o meu povo." 


\section{Interpretação do texto}

Verifica-se que a narrativa D11 não cumpre o número de linhas disponibilizadas nem o aluno "veste a pele" de um Senador Romano. A narrativa não apresenta um fio condutor, nem encadeamento entre as afirmações; é composta por frases curtas e simples, e não permite distinguir os três momentos fundamentais de uma composição escrita: introdução, desenvolvimento e conclusão.

Embora o aluno apresente esporadicamente algumas ideias retidas na aula quando escreve "Se eu fosse Senador gostava (...) de ir ao barbeiro, via espectáculos.", é evidente a dispersão e contradição de ideias "Tinha o poder de mandar em todos e quem desobedesse às minhas ordens era castigado. Não havia plebeus, eramos todos iguais."

Verifica-se que 0 aluno não aplica os conceitos históricos básicos relativos à sociedade romana e aos locais frequentados pelo seu personagem. Não faz contextualizações temporais, não localiza o Senador na pirâmide social nem refere os seus poderes nem as pessoas com quem convivia.

A narrativa do aluno é vaga e afasta-se do objetivo do enunciado bem como do acontecimento central "a importância de frequentares termas diariamente".

O aluno mostra falta de criatividade na sua narrativa e afastamento em relação ao objetivo da tarefa. Não consegue colocar-se no lugar de um Senador, abstrair-se do seu tempo atual e "experimentar" um tempo diferente aplicando as suas aprendizagens. Demonstrou também não ter recorrido a documentos estudados na aula nem às aprendizagens realizadas.

Por isso consideramos que a NA D11 se enquadra no nível 1, Fragmento, pois apresenta ideias fragmentadas e uma reduzida compreensão histórica da vida de um Senador situando-se, por isso, ainda num nível de Compreensão Muito Restrito.

\section{EXEMPLO 2 \\ Nível 2 - DESCRIÇÃO SIMPLES \\ Caracterização}

Narrativa com estrutura visível, apresentando ligações implícitas entre os passos. Pode apresentar também frases soltas ou vagas e, embora com uma argumentação simples, refira factos, acontecimentos e protagonistas, com vários detalhes e poucas referências espaciotemporais.

Representa pelo menos três tópicos do enunciado, e revela pouca compreensão histórica, logo pouco rigor histórico.

Narrativa pouco criativa.

Exemplo de narrativa dos alunos neste nível: NA C10. 


\section{Transcrição da NA C10}

"Eu sou o Imperador Nero sou alto, moreno, de cabelo castanho, bonito e elegante, sou lutador para obter Roma em primeiro lugar, gosto de mandar e de exercer todos os poderes enquanto Imperador, sou Rei Sol, porque por Roma ser a minha cidade e gosto muito de ter muitos pavilhões e jardins com quase cem hectares e gosto muito da minha estátua de trinta e cinco metros.

Sabes, enquanto Imperador de Roma possuo muitos poderes políticos que são poderes judiciais, poderes legislativos, poderes absolutos e muitos mais poderes.

As razões para conhecer a Domus Aurea é, porque tem muitas coisas bonitas e fala sobre coisas romanas como por exemplo, estradas romanas, pontes romanas, numeração romana, produtos de Roma, latim e demais coisas e também fala de mim, "O Imperador Nero".

Tenho uma coisa para vos contar, eu falei com os primos sobre as catacumbas romanas, a Domus Aurea e o Coliseu de Roma e contei tudo o que sabia e ficaram admirados quando souberam que eu era o Impera Nero.

Tudo começou assim, estava a passar pelo Coliseu de Roma e vi três adolescentes a passar pelo Coliseu e eles vieram ter comigo e disseram:

- Senhor, sabe tudo sobre Roma? - disseram os primos.

- Meninos, sei tudo - disse eu...

E lá eu contei tudo sobre a Domus Aurea, as Catacumbas Romanas, do Coliseu de Roma e tudo o que sabia sobre os romanos e de Roma.

- Icha, o senhor, sabe mesmo tudo? - disseram os primos.

- Sei, pois sou o imperador Nero - disse eu.

- É o Imperador que matou a sua mãe e as suas duas mulheres?- disse a Ana.

- Calada - disse Maria a Ana.

- Sabe como se chamava a Roménia naquela altura? - disse André.

- A Roménia chama-se Dácia - disse eu.

- Adeus - disse os primos.

- Adeus - disse eu.

Fiquei contente com aquela conversa que tive com os primos, de eles quererem saber tudo sobre Roma e de recordar o meu tempo de Imperador."

\section{Interpretação do texto}

A presente NA cumpre o número mínimo de linhas definidas, e o aluno assume 0 personagem de Imperador Romano "Eu sou o Imperador Nero (...) Sabes, enquanto Imperador de Roma possuo muitos poderes...."

Percebe-se que existe um fio condutor visível mas vago, entre os diferentes elementos da estrutura narrativa (introdução, desenvolvimento e conclusão). Quer isto dizer que, conseguimos demarcar, ainda que de forma pouco consistente, os elementos da estrutura narrativa: a introdução é muito descritiva, o desenvolvimento débil e a conclusão muito breve. Verifica-se que o aluno recorre a informação e conhecimentos adquiridos através 
das aulas e da obra literária estudada, porém, esses conhecimentos revelam-se nalgumas situações incoerentes.

No primeiro parágrafo é visível a descrição simples e dispersa que o aluno faz do Imperador Romano para além da dificuldade na construção frásica e na pontuação da mesma. $O$ aluno refere que o Imperador tem "poderes absolutos e muitos mais poderes" mas não revela quais nem qual a posição do Imperador na pirâmide social romana, demonstrando dessa forma alguma imprecisão e falta de domínio dessa informação histórica. 0 aluno procura também estabelecer uma relação causal, "sou Rei Sol, porque por Roma ser a minha cidade e gosto muito de ter muitos pavilhões e jardins com quase cem hectares...", ou seja, entre a extravagância e o esbanjamento de dinheiros públicos, mas a dificuldade em estabelecê-la torna-a implícita, reforçando a ideia da falta de domínio da informação.

Sem ligação explícita, o aluno inicia o desenvolvimento da narrativa. Verificam-se algumas afirmações vagas, como por exemplo, "As razões para conhecer a Domus Aurea é, porque tem muitas coisas bonitas e fala sobre coisas romanas...". No terceiro parágrafo da narrativa constatamos igualmente que 0 aluno tenta aplicar conhecimentos adquiridos na aula de História mas sem sucesso, como por exemplo quando afirma "As razões para conhecer a Domus Aurea é, porque tem muitas coisas bonitas e fala sobre coisas romanas como por exemplo, estradas romanas, pontes romanas, numeração romana, produtos de Roma, latim e demais coisas e também fala de mim, "O Imperador Nero", ou seja, o aluno limita-se a descrever os fatores de integração dos povos conquistados no Império Romano e associa-os à Domus Aurea e à sua decoração, revelando por isso, pouca compreensão histórica sobre o tema. Num outro momento refere "E lá eu contei tudo sobre a Domus Aurea, as Catacumbas Romanas, do Coliseu de Roma e tudo o que sabia sobre os romanos e de Roma.", mas não revela em momento algum o que de facto sabe sobre o assunto. Um outro exemplo "É o Imperador que matou a sua mãe e as suas duas mulheres? (...) Sabe como se chamava a Roménia naquela altura?" mostra que 0 aluno pretende acrescentar mais informação à sua narrativa (informação oriunda da obra infantojuvenil estudada), mas esta surge descontextualizada na lógica do seu texto e fragmentada, demonstrando novamente falta de domínio dessa informação. Neste último exemplo o aluno procura ainda estabelecer uma relação causal entre a personalidade de Nero e as consequências dos seus atos, ou seja, implicitamente pretende transmitir que o Imperador era tirano e maquiavélico, recorrendo a informação que the parece essencial.

A conclusão é visível mas muito sintética, "ôca". Não apresenta qualquer encadeamento com o momento anterior.

Em síntese podemos afirmar que a NA C10 apresenta uma estrutura visível com conteúdo descritivo e vago nalgumas situações. O aluno apesar de "vestir o papel" do Imperador Romano, é pouco criativo e não consegue revelar conhecimento histórico rigoroso na sua narrativa, apesar de recorrer a informações da obra literária infantojuvenil e a conhecimentos adquiridos na aula de História. Não obedece totalmente ao enunciado da atividade "Imagina (...) que surpreendias os Primos quando eles visitavam a Domus Aurea (...)", faz referências temporais imprecisas e não consegue relacionar factos e acontecimentos históricos. 
Por essas razões consideramos que a NA C10 se enquadra no nível 2, Descrição Simples, e o aluno demonstra uma Compreensão Ainda Restrita da situação histórica.

\section{EXEMPLO 3 \\ Nível 3 - DESCRIÇÃO EXPLICATIVA \\ Caracterização}

Narrativa elaborada com lógica interna, apresentando uma evidente estrutura narrativa, através de uma sequência organizativa coerente. Responde aos tópicos do enunciado e estabelece relações causais implícitas ou explícitas entre os factos, acontecimentos e protagonistas, fazendo referências espaciotemporais. Narrativa com detalhes, que revela compreensão histórica.

Narrativa criativa.

Exemplo de narrativa dos alunos neste nível: NA D6.

\section{Transcrição da NA D6}

"O meu nome é Caio Júlio César Octaviano, conhecido como César Augusto. Nasci no dia 27 de Setembro no ano de 63 a.C. em Roma, capital do Império Romano.

Sou filho de Caio Octávio Turino, edil, pretor e senador em Roma e procônsul na Macedônia e de Ácia Balba Cesônia. Meu tio-avô, Júlio César era o homem mais poderoso de Roma. Adoptou-me como filho em testamento. A 15 de março de 44 a.C. meu tio-avô foi assassinado enquanto eu estava em llínia a servir o exército. Retomei para Itália e fui informado que era herdeiro adoptivo de César. Casei-me com três mulheres: Clódia Pulcra, Escribrônia e Lívia Drusila. Tenho uma filha com Escribônia, que se chama Júlia a Maior.

Sou alto, tenho o corpo musculado, um rosto magro e uns olhos expressivos. Acho-me inteligente, batalhador, austero e conservador.

A minha dinastia ficou conhecida como Júlio-Claudiana. Comecei a governar o Império Romano a 16 de janeiro de 27 a.C.. Detenho o poder absoluto: poder executivo, legislativo e judicial. Sou comandante supremo do exército, tenho o direito de veto sobre as decisões do Senado, nomeo governadores para as províncias, mando cunhar a moeda e sou chefe da Religião Romana.

Durante o meu império impus a pax romana, ou seja, eliminamos a maior parte dos focos de resistência e das rebeliões através da força, aumentando assim a arrecadação tributária, para fortalecer as finanças públicas. No período em que reinei é considerado pelos historiadores um dos mais prósperos do Império Romano, tanto no tocante ao desenvolvimento económico quanto ao cultural.

Fui o primeiro Imperador Romano."

\section{Interpretação do texto:}

A NA D6 é o exemplo de uma unidade escrita com uma estrutura narrativa visível e consistente, que apresenta um fio condutor entre os diferentes momentos do texto. $\mathrm{O}$ aluno cumpre o número de linhas disponibilizadas para a realização da atividade, cumpre os objetivos do enunciado da tarefa, e é claro ao assumir o papel de Imperador quando afirma "O meu nome é Caio Júlio César Octaviano Augusto...". 
A narrativa é composta por frases simples, bem elaboradas, e que retratam o domínio da informação e os conhecimentos adquiridos através de várias fontes informativas.

Na introdução, o aluno faz uma apresentação histórica detalhada do seu personagem, com a preocupação de explicar as diferentes etapas do seu percurso social. Verifica-se que 0 aluno recorre a informação e conhecimentos adquiridos na aula de História e na internet (situação confirmada posteriormente em entrevista informal com o aluno), daí que, algumas delas sejam informações não essenciais como quando refere "(...), edil, pretor e senador em Roma e procônsul na Macedônia e de Ácia Balba Cesônia.” O aluno tem também o cuidado de coordenar referências temporais e espaciais como por exemplo "Nasci no dia 27 de Setembro no ano de 63 a.C. em Roma, capital do Império Romano." ou mais adiante quando refere "A 15 de março de 44 a.C. meu tio-avô foi assassinado enquanto eu estava em llínia a servir o exército.". No segundo parágrafo assinalamos um erro na referência a "Júlia a Maior", quando o aluno deveria escrever "Júlia a Velha".

No quarto parágrafo o aluno passa para o desenvolvimento da narrativa. É um texto sintético mas muito consistente em conteúdo histórico. Mais uma vez o aluno teve a preocupação de fazer referências espaciotemporais relativamente ao seu período de governo através da referência "A minha dinastia ficou conhecida como Júlio-Claudiana. Comecei a governar o Império Romano a 16 de janeiro de 27 a.C..", ou seja, além da curiosidade introduzida, dinastia Júlio-Claudiana, ainda coordenou as diferentes noções de espaço e de tempo.

Entre o quarto e o quinto parágrafo existe uma ligação lógica explícita, pois o aluno descreve os seus poderes no momento anterior e explica as suas ações e intenções no momento posterior. Fá-lo através da seguinte afirmação "Durante o meu império impus a pax romana, ou seja, eliminamos a maior parte dos focos de resistência e das rebelióes através da força, aumentando assim a arrecadação tributária, para fortalecer as finanças públicas.". Com esta frase, além da lógica interna, verificamos que o aluno revela uma compreensão histórica do assunto.

A conclusão é visível, embora o aluno a tenha iniciado ainda no momento do desenvolvimento da narrativa (quinto parágrafo). É sintética mas igualmente consistente quando o aluno se situa temporalmente e descreve o contexto da época. "No período em que reinei é considerado pelos historiadores um dos mais prósperos do Império Romano, tanto no tocante ao desenvolvimento económico quanto ao cultural. Fui o primeiro Imperador Romano." Apesar da estrutura frásica não estar totalmente correta, verifica-se que o aluno compreendeu o assunto e usa as ideias chave: quem foi o imperador Otávio Augusto e a grandiosidade do Império Romano.

Podemos então concluir que a NA D6 apresenta uma estrutura visível e o conteúdo tem uma lógica interna consistente. $\mathrm{O}$ aluno recorre a informação essencial e não essencial, descreve e explica situações históricas e não se afasta do objetivo principal do enunciado. Tem a preocupação de encadear os factos entre si, estabelecer relações causais implícitas e explícitas, e coordenar referências espaciotemporais. Apresenta encadeamento entre os diferentes elementos da estrutura narrativa e entre as informações retiradas da internet, do manual adotado e os conhecimentos adquiridos na aula de História. 
Por isso consideramos que a NA D6 enquadra-se no nível 3, Descrição Explicativa, e posiciona-se num nível de Compreensão Descritivo Explicativo da situação histórica.

\section{EXEMPLO 4}

\section{Nível 4 - DESCRIÇÃO EXPLICATIVA CONTEXTUALIZADA}

\section{Caracterização}

Narrativa elaborada com lógica interna, apresentando uma evidente estrutura narrativa, através de uma sequência organizativa coerente. Responde a todos os tópicos do enunciado, apresentando ligações causais implícitas e explícitas entre os acontecimentos, justifica as ações dos protagonistas fazendo interferir explicitamente as consequências e resultados desses acontecimentos e ações.

Narrativa com vários detalhes e com rigor histórico, que revela compreensão histórica da situação.

Narrativa muito criativa.

Exemplo de narrativa dos alunos neste nível: NA C6.

\section{Transcrição da NA C6}

"Olá! Eu sou o gladiador Negro. Eu, como quase todos os gladiadores, sou um lutador escravo treinado na Roma Antiga. Luto com outros gladiadores para divertir a plateia do Coliseu de Roma. Sou bem constituído e muito forte. Uso uma armadura e uma espada curta chamada gládio. Daí o nome "Gladiador". Não sou muito inteligente mas tenho uma enorme vontade de vencer.

De repente, comecei a ouvir uns barulhos. Então, saí do quadro onde estava pintado e segui os sons até me deparar com uma porta. Abri a porta e subi umas escadas. Então, apercebi-me de que estava no coliseu. O Coliseu é um edifício enorme. A parede exterior era formada por duas ordens de arcos, colocadas umas por cimas das outras. As passagens interiores eram feitas de pedra e betão. Antigamente, havia uma rede de corda suspensa por mastros de madeira por cima das bancadas. Quando estava sol excessivamente quente, colocavam uma cobertura de tela sobre a rede e quando estava a chover, toda a gente se abrigava nas passagens interiores. A arena, estava rebaixada alguns metros. No pavimento da arena, existia um tanque profundo que servia para simular batalhas navais. As bancadas seriam capazes de albergar vinte mil espectadores. As vozes tinham voltado:

- Eu quero aquele medalhão! - disse um homem alto.

- Eu sei, está com o Dragos. Aquele ali, mas fala baixo! - pediu o outro.

Então, descobri que não era o único que os estava a espiar. Do meu lado esquerdo, estavam três miúdos. Um rapaz e duas raparigas. la falar com eles, quando vi que um homem de camisa vermeIha os agarrou e os levou para baixo, junto do homem alto.

Estava impressionado com o sucedido. Primeiro, não acreditava no estado do coliseu e segundo, estava na presença de ladrões. Deduzi isso pois alguns tinham as caras tapadas e tinham paus muito grandes nas mãos.

Senti que tinha de fazer algo. Então, levantei-me e coloquei a espada na mão. Primeiro, atirei o homem da camisa vermelha ao chão, deixando-o inconsciente e depois cumprimentei os miúdos. 
- Eu sou o André, ela é a Ana e aquela é a Maria. Somos primos. - disse o miúdo.

- Eu sou um gladiador romano.

- Mas estamos no século XXI!

- Eu sei, eu saí de um quadro do Palácio Imperial. Vamos!

Então, dei um grito de luta e comecei a lutar contra os homens. Após dez minutos de luta, estavam já todos caídos no chão. Depois os Primos ligaram à polícia e esta prendeu-os a todos. Quanto a mim, voltei para o quadro com mais uma batalha cumprida.

Fim!"

\section{Interpretação do texto}

O aluno C6 apresenta uma unidade escrita com uma estrutura narrativa evidente (sobressaindo o elemento desenvolvimento), elaborada com lógica interna e coerência na informação escrita. Trata-se de uma narrativa que cumpre integralmente o limite máximo de linhas disponibilizadas para a realização da atividade bem como o objetivo e os tópicos do enunciado.

Embora a narrativa seja mais sintética que o exemplo anterior, o aluno demonstra ser bastante criativo perante este tipo de atividades e consegue apresentar factos históricos devidamente contextualizados e coordenados com informações adquiridas através de fontes diversas que 0 ajudam a desenrolar a narrativa.

Esta narrativa é composta por frases simples, coerentes, que demonstram a cada passo a empatia histórica do aluno com a situação histórica e o domínio da informação e os conhecimentos adquiridos através de várias fontes.

$\mathrm{Na}$ introdução, que ocupa o primeiro parágrafo, o aluno demonstra imediatamente que "veste" o personagem do Gladiador quando afirma "Olá! Eu sou o gladiador Negro.". Faz uma apresentação detalhada do seu personagem, tendo o cuidado de o situar no espaço e na pirâmide social romana, afirmando "Eu, como quase todos os gladiadores, sou um lutador escravo treinado na Roma Antiga. Luto com outros gladiadores para divertir a plateia do Coliseu de Roma.". Neste momento, é ainda possível verificar que o aluno recorre a conhecimentos adquiridos na aula de História, nomeadamente através da análise de documentos iconográficos sobre a imagem de um Gladiador, pois descreve-o como "bem constituído e muito forte. Uso uma armadura e uma espada curta chamada gládio. Daí o nome "Gladiador".

No parágrafo seguinte o aluno inicia o desenvolvimento da sua narrativa. É um momento extenso, detalhado e muito criativo. A descrição é tão criativa que o leitor consegue imaginar a cena que 0 aluno descreve, e, por momentos, deixar-se envolver por ela. 0 aluno viaja no tempo e coloca-se no meio da ação ao imaginar que "(...), saí do quadro onde estava pintado e segui os sons até me deparar com uma porta. Abri a porta e subi umas escadas. Então, apercebi-me de que estava no coliseu.". A partir daqui o aluno descreve pormenores da arquitetura romana, particularmente no Coliseu, "O Coliseu é um edifício enorme. A pare- 
de exterior era formada por duas ordens de arcos, colocadas umas por cimas das outras. As passagens interiores eram feitas de pedra e betão.", e acrescenta-lhe uma referência temporal que induz uma noção de tempo longínquo como "Antigamente (...)", e detalhes adquiridos através da obra infantojuvenil estudada na aula de História e noutras fontes secundárias, de forma coerente, "(...) havia uma rede de corda suspensa por mastros de madeira por cima das bancadas. Quando estava sol excessivamente quente, colocavam uma cobertura de tela sobre a rede e quando estava a chover, toda a gente se abrigava nas passagens interiores. A arena, estava rebaixada alguns metros. No pavimento da arena, existia um tanque profundo que servia para simular batalhas navais. As bancadas seriam capazes de albergar vinte mil espectadores.". Ou seja, o aluno acrescenta informação à sua descrição, estabelecendo relações causais implícitas, demonstrando domínio da informação e compreensão histórica da mesma. A coerência no discurso e a qualidade da construção frásica demonstram uma capacidade de elaboração mais elevada que os exemplos anteriores.

Entre todos os parágrafos existe uma ligação lógica explícita, pois o aluno descreve passo a passo a cena final da estória, explica as suas ações e ainda descreve reações e sentimentos despoletados pela situação. Fá-lo através da seguinte afirmação "Estava impressionado com o sucedido. Primeiro, não acreditava no estado do coliseu e segundo, estava na presença de ladróes (...) Senti que tinha de fazer algo (...) levantei-me (...) atirei o homem ao chão (...) cumprimentei os miúdos.”. Esta pormenorização coerente e explicativa da situação revela a preocupação do aluno em integrar a estória infantojuvenil estudada na sua narrativa, dando cumprimento ao último tópico do enunciado da atividade.

Ainda no desenvolvimento da narrativa, o aluno revela mais um pormenor que evidencia as transferências temporais na sua estória, isto é, entre a Roma Antiga e o tempo presente. Ou seja, o aluno consegue "vestir a pele" de um Gladiador, narra os acontecimentos devidamente contextualizados no tempo, mas em determinados momentos regressa ao tempo presente, nomeadamente quando refere no diálogo "Mas estamos no século XXI!".

A conclusão é evidente, sintética e coerente, e repete as transferências temporais realizadas pelo aluno quando afirma "Depois os Primos ligaram à polícia e esta prendeu-os a todos. Quanto a mim, voltei para o quadro com mais uma batalha cumprida.".

Em síntese, consideramos que a NA C6 apresenta uma estrutura visível e o conteúdo tem uma lógica interna consistente. $\mathrm{O}$ aluno recorre a informação essencial e descreve e explica situações históricas, cumprindo o objetivo do enunciado. Todos os parágrafos apresentam um encadeamento, e as descrições revelam relações causais implícitas e explícitas entre os acontecimentos. $\mathrm{O}$ aluno justifica a ação dos protagonistas e os resultados dos acontecimentos. Verifica-se igualmente que o aluno teve o cuidado de integrar informações retiradas da internet, do manual adotado e os conhecimentos adquiridos na aula de História através da obra O Mistério das Catacumbas Romanas.

Nesse sentido, consideramos que a NA C6 enquadra-se no nível 4, Descrição Explicativa Contextualizada, e posiciona-se num nível de Compreensão Explicativa Contextualizada da situação histórica. 
Assim, concluímos que no grupo de alunos do grupo experimental o uso da literatura infantojuvenil proporcionou uma aprendizagem mais "divertida" e revelou-se um estímulo à criatividade, à imaginação e à compreensão histórica dos conteúdos programáticos (Exemplo 4, NA C6). Do ponto de vista do professor, a utilização deste recurso e a implementação das metodologias inerentes ao processo de ensino-aprendizagem revelaram-se estimulantes e desafiadoras.

O teste de etapa, momento de avaliação sumativa, aplicado em ambas as turmas no final do segundo período letivo do ano 2012/2013, permitiu-nos recolher informações sobre o processo de ensino-aprendizagem e avaliar o contributo da utilização da literatura infantojuvenil nas aulas de História.

Ao analisarmos os resultados do grupo experimental e do grupo de controlo constatamos o elevado número de positivas: $96 \%$ dos discentes da turma do 7. $\mathrm{C}$ (ou seja, 25 alunos) obtiveram uma classificação positiva e um aluno obteve uma classificação inferior a 49 pontos. Na turma do 7.. D todos os alunos obtiveram classificação positiva. Todavia, podemos ainda inferir que:

- as questões que registaram maior sucesso apelavam à interpretação de fontes como mapas, gráficos, documentos históricos e excertos do livro O Mistério das Catacumbas Romanas (grupo experimental), o que nos permitiu concluir que o trabalho feito em contexto de aula para atingir as Metas de Aprendizagem (MA 6 e MA 8) surtiu um efeito positivo, tal como o uso da literatura infantojuvenil como recurso didático;

- as questões que geraram alguma dificuldade entre os alunos (cujas respostas foram definidas como respostas incompletas indiciam a sua dificuldade em interpretar e relacionar fontes e comunicarem historicamente (MA 12). Esta dificuldade é inferida a partir dos resultados do grupo experimental na questão 1.1. (Grupo II) que solicitava aos alunos a relação entre um mapa e um documento escrito (que foram analisados em contexto de aula), e, a partir dos resultados do grupo de controlo nas questões 1.1. e 1.2. (Grupo I) que apelavam à leitura de um mapa e à compreensão espacial (MA 4). Isto levou-nos a concluir que continuava a ser necessário reforçar a interpretação de fontes nas aulas e treinar a competência da comunicação escrita bem como o estabelecimento de relações entre os conteúdos (compreensão histórica contextualizada - MA 8).

Como já referimos, na fase final do nosso estudo aplicamos o questionário $A$ Literatura Infantojuvenil no ensino da História porque queríamos conhecer a opinião do grupo experimental sobre a utilização da literatura infantojuvenil na construção do seu conhecimento histórico, bem como a pertinência da continuidade do uso deste recurso didáticopedagógico nas aulas de História. Através deste questionário constatámos que, embora nem todos os alunos tenham lido a obra recomendada na íntegra, na generalidade concordaram que ela despertou a sua atenção e interesse e contribuiu para a aprendizagem de novos vocábulos e informação relacionados com o Império Romano. Entre os aspetos mais positivos das aulas lecionadas no mês de janeiro, os alunos referiram a utilização da obra 
infantojuvenil no processo de ensino-aprendizagem, e entre os menos positivos assinalaram que preferiam ver filmes e utilizar mais vezes o manual da disciplina, não apontando concretamente aspetos menos positivos sobre a obra O Mistério das Catacumbas Romanas. Por essa razão, metade da turma colocou a hipótese de se repetir a experiência num futuro próximo e 10 alunos não tinham dúvidas de que gostariam de ver novamente este tipo de recurso didático presente nas aulas de História no próximo ano letivo, pois consideram que a literatura infantojuvenil além de tornar as aulas mais agradáveis, contribui de facto para a aprendizagem dos alunos em História e desperta o seu interesse literário.

No final do nosso estudo concluímos que a nossa investigação respondeu a todas as questões orientadoras de forma positiva, provando que a utilização da literatura infantojuvenil nas aulas de História contribui claramente para as aprendizagens significativas dos alunos, e promove a compreensão histórica contextualizada.

Nesse sentido, pensamos que é possível promover a interdisciplinaridade entre as diferentes áreas do conhecimento nas escolas, neste caso, entre a História e o Português, dado que o livro O Mistério das Catacumbas Romanas integra o Plano Nacional de Leitura. O livro poderia ser igualmente explorado nas disciplinas de Geografia ou Ciências FísicoQuímica, podendo até promover a interdisciplinaridade em simultâneo, se os conteúdos programáticos estivessem atualizados e articulados vertical e horizontalmente.

Consideramos que é igualmente importante continuar a desenvolver investigação sobre o pensamento histórico dos alunos e a compreensão histórica contextualizada, quer através da leitura de literatura infantojuvenil ou até do romance histórico em níveis de escolaridade superiores. A leitura de estórias permite aos alunos identificar-se com os personagens e com o contexto da ação atribuindo um sentido às mensagens dos materiais históricos (compreensão histórica), e a produção de narrativas nas aulas de História permite ao aluno organizar a compreensão histórica sobre os acontecimentos, e o treino e o domínio da produção escrita e expressiva torna-os mais pensantes e mais críticos face ao presente e ao futuro.

\section{Bibliografia}

Armindo Teixeira Mesquita, "A leitura: um passaporte para vida". Álabe 3 (2011). (Disponível em: http://nevada.ual.es:81/alabe/index.php/alabe/article/view/45/45, consultado em 24/05/2013).

Breno Gontijo Andrade [et al.], "Empatia Histórica em sala de aula: relato e análise de uma prática complementar de se ensinar/aprender a História". Revista História \& Ensino 2, no 17 (2011): 257-282. (Disponível em: http://www.academia.edu/1855542/ Empatia_historica_em_sala_de_aula_relato_e_analise_de_uma_pratica_complementar_de_se_ensinar_aprender_a_historia, consultado em 27/08/2013).

DGEBS - Direção-Geral do Ensino Básico e Secundário, Programa de História. Plano de organização do ensino-aprendizagem: Ensino Básico - 3 Ciclo (Vol. II). (Lisboa: Ministério da Educação/Direção Geral do Ensino Básico e Secundário, 1991). 
Isabel Barca, "Narrativas e consciência histórica dos jovens". Revista de investigación didáctica, Enseñanza de las Ciencias Sociales no 10 (2010): 22-28. (Disponível em: http://www.raco.cat/index.php/EnsenanzaCS/article/view/248889, consultado em 27/08/2013).

Liliana Marlene Martins da Rocha, A Literatura Infantojuvenil na aula de História. Um estudo com alunos do 3. ciclo do Ensino Básico. Dissertação de Mestrado em Ensino de História e Geografia no 3. Ciclo do Ensino Básico e Secundário (Porto: Faculdade de Letras da Universidade do Porto, 2013). (Disponível em: https://sigarra.up.pt/ flup/pt/pub_geral.pub_view?pi_pub_base_id=28407, consultado em 04/01/2017).

Mafalda Moutinho, O mistério das catacumbas romanas. Coleção Os Primos, (Publicações Dom Quixote, (2011), 176.

Mafalda Moutinho, O segredo do mapa egípcio. Coleção Os Primos, (Publicações Dom Quixote, 2011), 256.

Raquel Alvarenga Sena Venera, Jonas Felisberto, Cristina Rachadel, "Desafios da Educação na Contemporaneidade: multidisciplinaridade entre Literatura e Ensino de História”. Revista Percursos 11, nำ (2010): 131-149. (Disponível em:

http://www.periodicos.udesc.br/index.php/percursos/article/viewFile/2054/1648, consultado em 02/01/2013).

Regina Parente, A Narrativa na Aula de História. Um estudo com alunos do 3ำ ciclo do Ensino Básico. Dissertação de Mestrado em Educação, Área de Supervisão Pedagógica em Ensino da História (Braga: Instituto de Educação e Psicologia da Universidade do Minho, 2004). (Disponível em: http://repositorium.sdum.uminho. pt/handle/1822/702, consultado em: 17/12/2012).

Regina Ribeiro, "A produção de narrativas em aulas de História". Anais Eletrônicos do IX Encontro Nacional dos Pesquisadores do Ensino de História. Brasil. (Disponível em: http://ieseccleston.buenosaires.edu.ar/RevistaN11delapena.pdf, consultado em 15/08/2013). 